\title{
ABO Blood Type Has No Impact on Survival in Patients with Epithelial Ovarian Cancer
}

\author{
Ling Wang 1, Zhuo Yang 2, Yi Liu 2, Ya-Nan Wang ${ }^{1}$, Jing-Yi Guo ${ }^{1}$, Qi-Jun Wu ${ }^{{ }^{凶}}$, Ting-Ting Gong ${ }^{2^{凶}}$ \\ 1. School of postgraduate, China Medical University, Shenyang, China. \\ 2. Department of Obstetrics and Gynecology, Shengjing Hospital of China Medical University, Shenyang, China. \\ 3. Department of Clinical Epidemiology, Shengjing Hospital of China Medical University, Shenyang, China. \\ $\square$ Corresponding authors: Qi-Jun Wu, M.D., Ph.D. Department of Clinical Epidemiology, Shengjing Hospital of China Medical University, No.36, SanHao \\ Street, Shenyang, Liaoning 110004, P. R. China. Phone: +86-24-96615-13648; Fax: +86-24-96615-13648; E-mail: wuqj@sj-hospital.org or Ting-Ting Gong, M.D. \\ Department of Obstetrics and Gynecology, Shengjing Hospital of China Medical University, No.36, SanHao Street, Shenyang, Liaoning 110004, P. R. China. \\ Phone: +86-24-96615-10132; Fax: +86-24-96615-10132; E-mail: gongtt@sj-hospital.org
}

( ) Ivyspring International Publisher. This is an open access article distributed under the terms of the Creative Commons Attribution (CC BY-NC) license (https://creativecommons.org/licenses/by-nc/4.0/). See http://ivyspring.com/terms for full terms and conditions.

Received: 2018.06.07; Accepted: 2018.08.28; Published: 2018.10.21

\begin{abstract}
Evidence for an association between $A B O$ blood type and epithelial ovarian cancer (EOC) survival has so far been limited and conflictive. This study applied a retrospective cohort and included 627 EOC patients diagnosed at Shengjing Hospital of China Medical University between 2011 and 2015. Adjusted hazard ratios (HRs) and $95 \%$ confidence intervals (Cls) between the $A B O$ blood type and progression-free survival (PFS) and overall survival (OS) of EOC patients were assessed using multivariable Cox proportional regression models. The median follow-up duration was 2.97 years (inter-quartile range from 2.11 to 4.13 years). The recurrence and mortality rates were $41.5 \%$ (260/627) and $37.0 \%$ (232/627), respectively. Possessing a comorbidity, residual disease, ascites, and advanced FIGO stage (III/IV) were associated with worse PFS and OS of EOC patients. The distribution of blood types $O, A, B$, and $A B$ among patients was $27.4 \%, 31.3 \%, 33.2 \%$, and $8.1 \%$, respectively. Compared with blood type $O$, none of the blood types $(A, B$, and $A B$ ) were significantly associated with PFS or OS. However, in the stratified analyses, we found borderline significant results for PFS with blood type $A B(H R=0.56,95 \% \mathrm{Cl}=0.31-1.01)$ compared with blood type $O$. No significant differences were observed for blood type $A$ when compared with all non-A blood type cases. This study does not support an association between $A B O$ blood type and EOC survival. Further prospective cohort studies are warranted to confirm our findings.
\end{abstract}

Key words: blood type; epithelial ovarian cancer; retrospective cohort; survival

\section{Introduction}

As the most fatal gynecological malignancy in women, epithelial ovarian carcinoma (EOC) was responsible for 22,240 new cases and 14,070 deaths in the United States in 2018 [1]. EOC lacks specific symptoms and early detection methods, and thus the prognosis is often unfavorable [2]. For example, the case-fatality ratios for this disease in 2010, as observed in China, were $32.23 \%$ and $67.20 \%$ among women diagnosed at $<65$ and $\geq 65$ years of age, respectively [3]. Currently, a growing number of potential prognostic factors (e.g. tumor grade, residual disease, stage) are being examined in growing efforts to predict the survival of patients with EOC. However, a proportion of patients with similar clinicopathologic characteristics remain to present with different survival outcomes. Kim and colleagues [4] successfully characterized the genomic landscape and identified the complex genomic alterations associated with ovarian clear cell carcinoma. Such findings prompted the investigation of potential genetic factors, including the BRAF mutation [5]. Furthermore, there have also been investigations studying potential roles of $\mathrm{ABO}$ blood type [6-8].

$\mathrm{ABO}$ blood type is reported to be a key genetic 
factor in the development and progression of multiple diseases [9]. Recently, a meta-analysis of observational studies provided some evidence for an association between $\mathrm{ABO}$ blood group and the risk of cancer [10]. Furthermore, there are some studies investigating the role of $\mathrm{ABO}$ blood types as prognostic biomarkers in several different types of cancers including breast cancer [11] and cervical cancer [12]. However, evidence for the prognostic value of this biomarker in EOC patients has been limited. To the best of our knowledge, only three epidemiological studies have been published that focused on this issue with controversial results. For example, in 1995, Marinaccio and colleagues [6] reported that blood type O EOC cases showed increased 5-year survival rates compared with other blood types in a small Italian study $(\mathrm{n}=92)$. Ten years later, Zhou and coworkers [7] reported that blood type A was associated with significantly worse overall survival (OS) rates compared with non-A blood type on the basis of a retrospective cohort including 256 Chinese EOC patients. By contrast, Cozzi and colleagues [8] subsequently reported that blood type A was associated with significantly better OS compared with both blood type $\mathrm{O}$ and all non-A blood type cases in a retrospective cohort study $(\mathrm{n}=694$, predominantly Caucasian cases).

These conflicting results might be attributed to the limited number of cases studied, the heterogeneity of patients, and differences in $\mathrm{ABO}$ blood type distribution. Therefore, to further clarify the association between $\mathrm{ABO}$ blood type and survival of EOC patients, we conducted a retrospective study at Shengjing Hospital of China Medical University.

\section{Material and Methods}

\section{Study population}

With the approval of the Institutional Review Board of the Ethics Committee of Shengjing Hospital of China Medical University (2015PS38K), we conducted this retrospective study of EOC patients at Shenging Hospital of China Medical University, Shenyang, China, between December 1, 2011 and December 31, 2015. Patients were included that had been diagnosed with primary EOC. The patient exclusion criteria were as follows: 1) patients had non-epithelial or non-ovarian malignancies; 2) those being treated for recurrent disease; 3 ) those who had undergone surgical exploration at another institution but received chemotherapy at Shengjing Hospital; 4) those who had received neoadjuvant therapy or intraperitoneal chemotherapy; 5) those under 15 years of age; and 6) those with incomplete data for the variables or covariates analyzed in this study.

\section{Data collection}

Based on the electronic medical records from the hospital information system of Shengjing Hospital, we collected the following demographic and clinical variables: age at diagnosis, histological type, comorbidities, International Federation of Gynecology and Obstetrics (FIGO) stage, residual disease, ascites, tumor grade, and treatment. We serologically examined the $\mathrm{ABO}$ blood group type of all enrolled patients before surgery using the Diamed blood type identification card (micro column gel method).

The data detailed above were collected by experienced gynecologists and pathologists. Tumor stage and grade were calculated according to the FIGO criteria and the histologic typing system of the WHO, respectively [13]. Tumors were graded as well $\left(G_{1}\right)$, moderately $\left(G_{2}\right)$, or poorly $\left(G_{3}\right)$ differentiated [14]. Residual disease was divided into either 'none detectable' when no disease was visible following surgery, or if visible disease remained, as ' $\leq 1 \mathrm{~cm}^{\prime}$ and '> $1 \mathrm{~cm}^{\prime}$ according to the size of the disease. Performance status was evaluated according to the criteria of the Eastern Cooperative Oncology Group's (ECOG) scale (0-5 scores) [15]. Information on comorbidities present prior to EOC diagnosis was obtained, which was classified as 'yes' or 'no' according to the Charlson comorbidity index [16].

\section{Follow-up and outcome}

After surgical treatment, all of the patients were followed up by telephone contact or by an interview at the clinic. In accordance with the Response Evaluation Criteria in Solid Tumors (RECIST), evaluation of the clinical progression of disease was based on clinical examination, a serum CA-125 assay, chest x-ray, abdominal-pelvic ultrasound, and computed tomography scan. Additional investigations were performed when appropriate. The primary endpoint was progression-free survival (PFS), defined as the time from completion of primary surgery to the first progression or recurrence of disease or death from any cause. OS was defined as the time from the completion of primary surgery to death from any cause or the date of last follow-up (December 31, 2017) for patients who were still alive. The cause of death was obtained from the death certificates.

\section{Statistical analysis}

The Mann-Whitney $U$ and Chi-square tests were used to compare continuous and category variables among different blood types, respectively. Continuous variables were summarized as the median with the inter-quartile range (IQR). Categorical variables were expressed as numbers along with percentages. The Cox Proportional Hazards Model was applied to 
estimate the hazard ratios (HRs) and 95\% confidence intervals (CIs). We assessed the proportional hazards assumption with a likelihood ratio test. $\mathrm{ABO}$ blood type was categorized into $\mathrm{A}, \mathrm{B}, \mathrm{AB}$, and $\mathrm{O}$ groups. Furthermore, we categorized $\mathrm{ABO}$ blood type into A and non-A group according to published studies [6-8].

We conducted multivariable adjusted analyses, including the following potential confounders: age at diagnosis, FIGO stage, residual disease, comorbidities, performance status, ascites, and cancer grading. Furthermore, we carried out subgroup analyses stratified by the aforementioned potential confounders. Likelihood ratio tests were conducted to examine whether the associations between $\mathrm{ABO}$ blood type and PFS and OS were modified by the following pre-specified potential effect modifiers: FIGO stage, residual disease, comorbidity, performance status, ascites, and cancer grading. In sensitivity analyses, we further excluded: patients who had recurrence of disease or died within 1 year of study enrollment. A $P$-value $<0.05$ was considered statistically significant.
All analyses were performed using SAS software (version 9.3; SAS Institute, Cary, NC, USA).

\section{Results}

\section{Patient characteristics}

A flow chart of patients excluded and included in the study is shown in Figure 1. Finally, a total of 627 consecutive patients with EOC were included in the main analysis. The median age of these patients was 53 (IQR: 48 to 59). After a median observation period of 2.97 years (IQR: 2.11 to 4.13 years), 260 (41.5\%) had recurrent disease and $232(37 \%)$ patients died. The demographic and clinical characteristics of EOC patients according to $\mathrm{ABO}$ blood type is shown in Table 1 . The distribution of blood types $\mathrm{O}, \mathrm{A}, \mathrm{B}$, and $\mathrm{AB}$ was $27.4 \%, 31.3 \%, 33.2 \%$, and $8.1 \%$, respectively. However, no significant differences with respect to ABO blood type were detected regarding patient's demographic and clinical characteristics.

Table 1. Selected demographic and clinical characteristics of ovarian cancer patients according to ABO blood type

\begin{tabular}{|c|c|c|c|c|c|}
\hline \multirow[t]{2}{*}{ Variables } & \multicolumn{4}{|c|}{ ABO blood type } & \multirow[t]{2}{*}{$P$ value $\dagger$} \\
\hline & Type O & Type A & Type B & Type AB & \\
\hline No. of patients & 172 & 196 & 208 & 51 & \\
\hline Age at diagnosis (years), Mean (IQR) & $52(47.5-59)$ & $52(47-59)$ & $54(47-61)$ & $51(46-59)$ & 0.82 \\
\hline Follow-up time (years), Median (IQR) & $3.1(2.2-4.5)$ & $3.0(2.2-4.2)$ & $3.0(2.1-4.1)$ & $3.0(2.5-3.6)$ & 0.76 \\
\hline Vital status (\%) & & & & & 0.58 \\
\hline Alive & $111(64.5)$ & $119(60.7)$ & $129(62.0)$ & $36(70.6)$ & \\
\hline Died & $61(35.5)$ & $77(39.3)$ & $79(38.0)$ & $15(29.4)$ & \\
\hline Recurrence status (\%) & & & & & 0.91 \\
\hline Yes & $75(43.6)$ & $79(40.3)$ & $86(41.4)$ & $20(39.2)$ & \\
\hline No & $97(56.4)$ & $117(59.7)$ & $122(58.7)$ & $31(60.8)$ & \\
\hline Histological type $(\%)$ & & & & & 0.87 \\
\hline Serous & $119(69.2)$ & $143(73)$ & $150(72.1)$ & $37(72.6)$ & \\
\hline Non-serous & $53(30.8)$ & $53(27)$ & $58(27.9)$ & $14(27.5)$ & \\
\hline Comorbidity (\%) & & & & & 0.67 \\
\hline No & $86(50)$ & $108(55.1)$ & $110(52.9)$ & $24(47.1)$ & \\
\hline Yes & $86(50)$ & $88(44.9)$ & $98(47.1)$ & $27(52.9)$ & \\
\hline Performance status (\%) & & & & & 0.08 \\
\hline 0 & $1(0.6)$ & 0 & $1(0.5)$ & $2(3.9)$ & \\
\hline 1 & $49(28.5)$ & $47(24)$ & $48(23)$ & $12(23.5)$ & \\
\hline 2 & $87(50.5)$ & $94(48)$ & $105(50.5)$ & $31(60.8)$ & \\
\hline$\geq 3$ & $35(20.4)$ & $55(28)$ & $54(26)$ & $6(11.8)$ & \\
\hline FIGO stage $(\%)$ & & & & & 0.91 \\
\hline I & $55(32)$ & $54(27.6)$ & $53(25.5)$ & $12(23.5)$ & \\
\hline II & $22(12.8)$ & $29(14.8)$ & $32(15.4)$ & $8(15.7)$ & \\
\hline III & $84(48.8)$ & $100(51)$ & $104(50)$ & $28(54.9)$ & \\
\hline IV & $11(6.4)$ & $13(6.6)$ & $19(9.1)$ & $3(5.9)$ & \\
\hline Residual disease (\%) & & & & & 0.97 \\
\hline None detectable & $112(65.1)$ & $122(62.2)$ & $131(63)$ & $30(58.8)$ & \\
\hline$\leq 1 \mathrm{~cm}$ & $31(18)$ & $34(17.4)$ & $38(18.3)$ & $11(21.6)$ & \\
\hline$>1 \mathrm{~cm}$ & 29 (16.9) & $40(20.4)$ & 39 (18.7) & $10(19.6)$ & \\
\hline Ascites (\%) & & & & & 0.23 \\
\hline No & 68 (39.5) & $87(44.4)$ & $90(43.3)$ & $15(29.4)$ & \\
\hline Yes & $104(60.5)$ & 109 (55.6) & $118(56.7)$ & $36(70.6)$ & \\
\hline Grading (\%) & & & & & 0.10 \\
\hline Grade 1 & $14(8.1)$ & $7(3.6)$ & $12(5.8)$ & $3(5.9)$ & \\
\hline Grade 2 & 48 (27.9) & 43 (21.9) & $67(32.2)$ & $11(21.6)$ & \\
\hline Grade 3 & $110(64.0)$ & $146(74.5)$ & $129(62)$ & 37 (72.6) & \\
\hline
\end{tabular}

$\mathrm{IQR}$, inter-quartile range.

† The Mann-Whitney $U$ and Chi-square test were used for comparing continuous and category variables, respectively. 


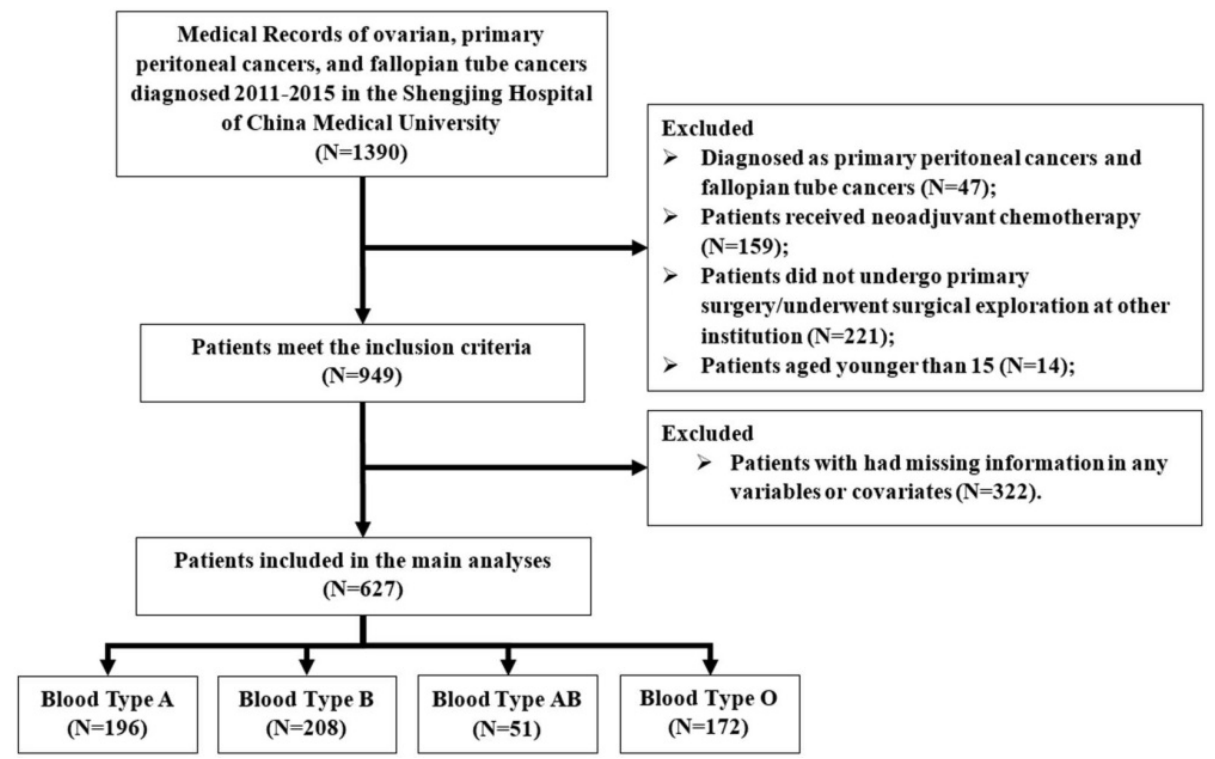

Figure 1. Flow diagram of the study population. Exclusion criteria are described on the right.

Table 2. Selected demographic and clinical characteristics according to progression-free survival and overall survival among ovarian cancer patients

\begin{tabular}{|c|c|c|c|c|}
\hline \multirow[t]{2}{*}{ Variables } & \multicolumn{2}{|l|}{ PFS } & \multicolumn{2}{|l|}{ OS } \\
\hline & No./Events & HR $(95 \% \mathrm{CI})^{\dagger}$ & No./Events & HR $(95 \% \mathrm{CI})^{\dagger}$ \\
\hline \multicolumn{5}{|c|}{ Age at diagnosis } \\
\hline$\leq 50$ & $257 / 101$ & 1.00 (Ref) & $257 / 85$ & 1.00 (Ref) \\
\hline$>50$ & $370 / 159$ & $1.11(0.86-1.44)$ & $370 / 147$ & $1.26(0.95-1.65)$ \\
\hline \multicolumn{5}{|c|}{ Comorbidity } \\
\hline No & $328 / 119$ & 1.00 (Ref) & $328 / 102$ & 1.00 (Ref) \\
\hline Yes & 299/141 & $1.36(1.06-1.75)$ & $299 / 130$ & $1.50(1.15-1.95)$ \\
\hline \multicolumn{5}{|c|}{ Performance status } \\
\hline $0-1$ & $161 / 63$ & 1.00 (Ref) & $161 / 52$ & 1.00 (Ref) \\
\hline 2 & $317 / 116$ & $0.98(0.71-1.35)$ & $317 / 103$ & $1.11(0.78-1.57)$ \\
\hline$\geq 3$ & $149 / 81$ & $1.38(0.96-1.98)$ & $149 / 77$ & $1.42(0.97-2.08)$ \\
\hline \multicolumn{5}{|c|}{ Histological type (\%) } \\
\hline Serous & $449 / 212$ & 1.00 (Ref) & $449 / 187$ & 1.00 (Ref) \\
\hline Non-serous & $178 / 48$ & $0.79(0.57-1.11)$ & $178 / 45$ & $0.93(0.66-1.32)$ \\
\hline \multicolumn{5}{|c|}{ FIGO stage (\%) } \\
\hline I-II & $265 / 52$ & 1.00 (Ref) & $265 / 39$ & 1.00 (Ref) \\
\hline III-IV & $362 / 208$ & $2.68(1.88-3.80)$ & $362 / 193$ & $3.27(2.22-4.82)$ \\
\hline \multicolumn{5}{|c|}{ Residual disease } \\
\hline $\begin{array}{l}\text { None } \\
\text { detectable }\end{array}$ & $395 / 114$ & 1.00 (Ref) & $395 / 92$ & 1.00 (Ref) \\
\hline$\leq 1 \mathrm{~cm}$ & $114 / 68$ & $1.97(1.43-2.72)$ & $114 / 64$ & $2.05(1.46-2.88)$ \\
\hline$>1 \mathrm{~cm}$ & $118 / 78$ & $2.01(1.46-2.76)$ & $118 / 76$ & $2.37(1.71-3.30)$ \\
\hline \multicolumn{5}{|l|}{ Ascites } \\
\hline No & $367 / 129$ & 1.00 (Ref) & $367 / 110$ & 1.00 (Ref) \\
\hline Yes & 260/131 & $1.09(0.83-1.43)$ & $260 / 122$ & $1.31(1.00-1.74)$ \\
\hline \multicolumn{5}{|l|}{ Grading } \\
\hline Grade 1 & $36 / 12$ & 1.00 (Ref) & $36 / 9$ & 1.00 (Ref) \\
\hline Grade 2 & $169 / 64$ & $1.40(0.77-2.55)$ & $169 / 55$ & $1.70(0.85-3.40)$ \\
\hline Grade 3 & $422 / 184$ & $1.58(0.83-3.00)$ & $422 / 168$ & $1.79(0.73-4.36)$ \\
\hline
\end{tabular}

\section{Multivariate analyses of the demographic and clinical characteristics}

Table 2 summarizes selected patient characteristics in relation to PFS and OS after mutual adjustment. In multivariable analysis, comorbidity $(\mathrm{HR}=1.36$, $95 \% \mathrm{CI}=1.06-1.75)$, FIGO stage III/IV $(\mathrm{HR}=2.68$, $95 \% \mathrm{CI}=1.88-3.80)$, residual disease $\leq 1 \mathrm{~cm}(\mathrm{HR}=$ $1.97,95 \% \mathrm{CI}=1.43-2.72)$, and residual disease $>1 \mathrm{~cm}$ $(\mathrm{HR}=2.01,95 \% \mathrm{CI}=1.46-2.76)$ were significantly associated with inferior PFS (Table 2). Additionally, comorbidity $(\mathrm{HR}=1.50,95 \% \mathrm{CI}=1.15-1.95)$, FIGO stage III/IV ( $\mathrm{HR}=3.27,95 \% \mathrm{CI}=2.22-4.82)$, residual disease $\leq 1 \mathrm{~cm}(\mathrm{HR}=2.05,95 \% \mathrm{CI}=1.46-2.88)$, and residual disease $>1 \mathrm{~cm}(\mathrm{HR}=2.37,95 \% \mathrm{CI}=1.71-3.30)$ remained independent and significant risk factors for poorer OS. Of note, the presence of ascites $(\mathrm{HR}=1.31$, $95 \% \mathrm{CI}=1.00-1.74)$ was associated with poorer outcomes in EOC patients.

\section{Association of $A B O$ blood type and survival of EOC patients}

For PFS, compared with blood type O, the HRs for blood types $\mathrm{A}, \mathrm{B}$, and $\mathrm{AB}$ were $0.87(95 \% \mathrm{CI}=$ $0.63-1.20), 0.83$ (95\% CI $=0.60-1.15)$, and 0.71 (95\% CI $=0.43-1.18)$, respectively, after adjustment for potential confounders including age at diagnosis, FIGO, residual disease, performance status, ascites, and grading (Table 3). In the stratified analyses, although there was no significant interaction effect, we observed borderline significant results for blood type $\mathrm{AB}$ in EOC patients with advanced stage disease $(\mathrm{HR}=0.56,95 \% \mathrm{CI}=0.31-1.01)$. Non-significant results were observed throughout the analysis for OS (Table 4). Additionally, when categorizing ABO blood 
type into A and non-A groups, we failed to detect significant results either for PFS or OS (Table 5).

In the sensitivity analyses, we excluded 127 patients who showed recurrence within 1 year of study enrollment and 52 patients who died within 1 year of study enrollment. The PFS and OS rates were similar to the findings presented above.

\section{Discussion}

The potential impact of $\mathrm{ABO}$ blood type on outcomes in EOC patients has been a matter of debate with contradictory results being reported. Therefore, we conducted a retrospective study to evaluate this issue further. The current study failed to detect any significant impact of blood types $\mathrm{A}, \mathrm{B}$, and $\mathrm{AB}$ on PFS or OS compared with patients with blood type $\mathrm{O}$. Furthermore, no significant differences were detected for blood type A when compared with all non-A blood type cases.
Our findings did not support any of the previous three studies [6-8]. The first study by Marinaccio and colleagues [6] found that blood type $\mathrm{O}$ was associated with longer 5-year survival rates among EOC patients in Italy; however, the sample size was small. Over recent years, two hospital-based retrospective studies were carried out that generated completely contradictory results $[7,8]$. Several possible explanations might account for this discrepancy. The characteristics of the ovarian cancer patients included in each study were different. Patients with FIGO IV were excluded from the study performed by Zhou and coworkers [7]. Whereas, the cases included in the study by Cozzi and colleagues [8] were predominantly Caucasian (89.3\%). The distribution of $\mathrm{ABO}$ blood types also differed among these studies. Blood types A, B, O, and $\mathrm{AB}$ accounted for $23.4 \%, 20.3 \%, 46.9 \%$, and $9.4 \%$ of cases, respectively, in the study by Zhou and colleagues [7], compared with $45.0 \%, 12.2 \%, 37.2 \%$, and $5.6 \%$, respectively, in the study by Cozzi and coworkers [8].

Table 3. Hazard ratio $(95 \% \mathrm{Cl})$ for progression-free survival among ovarian cancer patients according to ABO blood type

\begin{tabular}{|c|c|c|c|c|c|}
\hline & \multicolumn{4}{|c|}{ ABO blood type } & \multirow{3}{*}{$P$ value for Interaction } \\
\hline & Type O & Type A & Type B & Type AB & \\
\hline & HR $(95 \% \mathrm{CI}) \dagger$ & HR $(95 \% \mathrm{CI}) \dagger$ & HR $(95 \% \mathrm{CI}) \dagger$ & HR $(95 \% \mathrm{CI}) \dagger$ & \\
\hline All patients & 1.00 (Ref) & $0.87(0.63-1.20)$ & $0.83(0.60-1.15)$ & $0.71(0.43-1.18)$ & \\
\hline FIGO stage & & & & & 0.16 \\
\hline I-II & 1.00 (Ref) & $1.53(0.73-3.17)$ & $1.01(0.46-2.24)$ & $1.63(0.56-4.74)$ & \\
\hline III-IV & 1.00 (Ref) & $0.74(0.51-1.07)$ & $0.78(0.55-1.11)$ & $0.56(0.31-1.01)$ & \\
\hline Histological type & & & & & 0.42 \\
\hline Serous & 1.00 (Ref) & $0.93(0.65-1.35)$ & $0.84(0.59-1.21)$ & $0.85(0.49-1.48)$ & \\
\hline Non-serous & 1.00 (Ref) & $0.64(0.30-1.38)$ & $0.87(0.42-1.80)$ & $0.25(0.06-1.04)$ & \\
\hline Residual disease & & & & & 0.35 \\
\hline None detectable & 1.00 (Ref) & $0.91(0.56-1.49)$ & $0.69(0.42-1.14)$ & $1.08(0.54-2.17)$ & \\
\hline$\leq 1 \mathrm{~cm}$ & 1.00 (Ref) & $0.67(0.34-1.26)$ & $0.96(0.51-1.81)$ & $0.43(0.14-1.32)$ & \\
\hline$>1 \mathrm{~cm}$ & 1.00 (Ref) & $0.85(0.46-1.58)$ & $0.74(0.40-1.38)$ & $0.47(0.16-1.41)$ & \\
\hline Comorbidity & & & & & 0.98 \\
\hline Yes & 1.00 (Ref) & $0.94(0.60-1.46)$ & $0.81(0.52-1.25)$ & $0.67(0.35-1.29)$ & \\
\hline No & 1.00 (Ref) & $0.82(0.51-1.32)$ & $0.86(0.53-1.38)$ & $0.71(0.31-1.63)$ & \\
\hline
\end{tabular}

Table 4. Hazard ratio $(95 \% \mathrm{Cl})$ for overall survival among ovarian cancer patients according to ABO blood type

\begin{tabular}{|c|c|c|c|c|c|}
\hline & \multicolumn{4}{|c|}{ ABO blood type } & \multirow{3}{*}{$P$ value for Interaction } \\
\hline & Type O & Type A & Type B & Type AB & \\
\hline & HR (95\%CI)† & HR (95\%CI)† & HR $(95 \% \mathrm{CI}) \dagger$ & HR $(95 \% C I) \dagger$ & \\
\hline All patients & 1.00 (Ref) & $1.05(0.74-1.48)$ & $1.02(0.72-1.44)$ & $0.77(0.43-1.36)$ & \\
\hline FIGO stage & & & & & 0.59 \\
\hline I-II & 1.00 (Ref) & $1.37(0.62-3.05)$ & $0.94(0.39-2.26)$ & $0.84(0.18-3.90)$ & \\
\hline III-IV & 1.00 (Ref) & $0.97(0.66-1.42)$ & $1.01(0.69-1.48)$ & $0.74(0.40-1.37)$ & \\
\hline Histological type & & & & & 0.74 \\
\hline Serous & 1.00 (Ref) & $1.11(0.75-1.65)$ & $1.02(0.69-1.52)$ & $0.68(0.35-1.34)$ & \\
\hline Non-serous & 1.00 (Ref) & $0.75(0.34-1.64)$ & $0.96(0.45-2.07)$ & $1.00(0.32-3.12)$ & \\
\hline Residual disease & & & & & 0.75 \\
\hline None detectable & 1.00 (Ref) & $1.30(0.76-2.24)$ & $1.00(0.57-1.76)$ & $1.04(0.42-2.59)$ & \\
\hline$\leq 1 \mathrm{~cm}$ & 1.00 (Ref) & $0.83(0.42-1.64)$ & $0.96(0.49-1.87)$ & $0.47(0.15-1.43)$ & \\
\hline$>1 \mathrm{~cm}$ & 1.00 (Ref) & $0.75(0.40-1.40)$ & $0.72(0.38-1.37)$ & $0.80(0.28-2.31)$ & \\
\hline Comorbidity & & & & & 0.57 \\
\hline Yes & 1.00 (Ref) & $1.17(0.73-1.87)$ & $1.23(0.77-1.97)$ & $0.65(0.31-1.37)$ & \\
\hline No & 1.00 (Ref) & $0.90(0.54-1.49)$ & $0.79(0.47-1.33)$ & $0.98(0.40-2.43)$ & \\
\hline
\end{tabular}

CI, confidence interval; FIGO, International Federation of Gynecology and Obstetrics; HR, hazard ratio.

† HRs ( $95 \%$ CIs) for overall survival were estimated by using multivariable proportional hazard models that were adjusted for age at diagnosis, FIGO, residual disease, performance status, ascites, and grading. 
Table 5. Hazard ratio $(95 \% \mathrm{Cl})$ for progression-free and overall survival among ovarian cancer patients according to $\mathrm{A}$ and non-A blood type

\begin{tabular}{|c|c|c|c|c|c|c|}
\hline & \multicolumn{3}{|c|}{ Progression-free survival } & \multicolumn{3}{|c|}{ Overall survival } \\
\hline & \multicolumn{2}{|l|}{ Blood type } & \multirow{3}{*}{$\begin{array}{l}P \text { value for } \\
\text { Interaction }\end{array}$} & \multicolumn{2}{|l|}{ Blood type } & \multirow{3}{*}{$\begin{array}{l}P \text { value for } \\
\text { Interaction }\end{array}$} \\
\hline & Non-Type A & Type A & & Non-Type A & Type A & \\
\hline & HR $(95 \% \mathrm{CI}) \dagger$ & HR $(95 \% \mathrm{CI}) \dagger$ & & HR $(95 \% \mathrm{CI}) \dagger$ & HR $(95 \% \mathrm{CI}) \dagger$ & \\
\hline All patients & 1.00 (Ref) & 0.99 (0.75-1.29) & & 1.00 (Ref) & 1.07 (0.81-1.41) & \\
\hline FIGO stage & & & 0.10 & & & 0.17 \\
\hline I-II & 1.00 (Ref) & $1.43(0.80-2.55)$ & & 1.00 (Ref) & $1.44(0.75-2.74)$ & \\
\hline III-IV & 1.00 (Ref) & $0.90(0.66-1.22)$ & & 1.00 (Ref) & 0.99 (0.73-1.35) & \\
\hline Histological type & & & 0.54 & & & 0.34 \\
\hline Serous & 1.00 (Ref) & $1.04(0.77-1.40)$ & & 1.00 (Ref) & $1.15(0.85-1.56)$ & \\
\hline Non-serous & 1.00 (Ref) & $0.76(0.37-1.55)$ & & 1.00 (Ref) & $0.76(0.38-1.55)$ & \\
\hline Residual disease & & & 0.60 & & & 0.40 \\
\hline None detectable & 1.00 (Ref) & $1.08(0.72-1.61)$ & & 1.00 (Ref) & $1.29(0.84-1.99)$ & \\
\hline$\leq 1 \mathrm{~cm}$ & 1.00 (Ref) & $0.73(0.41-1.30)$ & & 1.00 (Ref) & $0.91(0.52-1.61)$ & \\
\hline$>1 \mathrm{~cm}$ & 1.00 (Ref) & $1.09(0.67-1.79)$ & & 1.00 (Ref) & $0.92(0.56-1.51)$ & \\
\hline Comorbidity & & & 0.69 & & & 0.79 \\
\hline Yes & 1.00 (Ref) & $1.09(0.44-2.70)$ & & 1.00 (Ref) & $1.11(0.76-1.61)$ & \\
\hline No & 1.00 (Ref) & $0.92(0.62-1.36)$ & & 1.00 (Ref) & $1.01(0.66-1.54)$ & \\
\hline
\end{tabular}

The exact underlying mechanism by which $\mathrm{ABO}$ blood group influences cancer progression remains unclear. However, a growing body of evidence highlights some plausible mechanisms that may contribute to this phenomenon. The $\mathrm{ABO}$ gene is located on chromosome 9q34 encoding several glycosyl transferases that add sugar residues to the $\mathrm{H}$ $(\mathrm{O})$ antigen to form $\mathrm{ABO}$ antigens. The $\mathrm{H}(\mathrm{O})$ antigen binds to von Willebrand factor (vWF), which is a protein for coagulation factor VIII (FVIII) $[17,18]$. The plasma levels of vWF and FVIII are directly proportional to the risk of thrombosis [19-21]. Previous studies suggested that thrombosis has poor prognostic value in terms of the survival of aggressive tumors $[17,22,23]$. In addition, due to the dysfunction of $\mathrm{ABO}$ enzymatic activity, $\mathrm{ABO}$ antigens contribute to cancer development and progression by modifying cell adhesion, membrane signaling, and immune responses [24,25]. While some studies demonstrated that hypermethylation of the $\mathrm{ABO}$ gene promoter induces the loss of $\mathrm{ABO}$ antigen expression on cancer cells, thereby increasing their motility and resistance to apoptosis, aiding immune evasion. All of the above alterations therefore may accelerate tumor invasion and metastasis [24-27]. The plasma levels of several pro-inflammatory and adhesion molecules (i.e. soluble E-selectin, P-selectin, vWF) are regulated by ABO blood type $[9,20,27,28]$, as well as soluble intercellular adhesion molecule 1 [9,29]. Moreover, chronic inflammation, which affects the malignant and metastatic spread of tumors, is also a prognostic indicator of carcinoma [30,31].

Our study has several strengths. To the best of our knowledge, this is the largest study exploring the prognostic value of $\mathrm{ABO}$ blood type in EOC in Asia, as well as in China. Furthermore, we carried out numerous subgroup analyses stratified by these well-established prognostic factors as well as sensitivity analyses to confirm that the findings were robust. However, our study did have several limitations. Firstly, the retrospective nature of the study and the fact that the data originated from a single center should be acknowledged. Although data were collected from prospectively maintained electronic medical records, it is possible that errors may occur. Moreover, potential recall and confounding bias may be inherited. However, in 2014, Shengjing Hospital of China Medical University became the only "Dual Seven Level" hospital in China reaching level 7 of the Electronic Medical Record System Application Capacity Grading by the Hospital Management Institute of the National Health and Family Planning Commission and level 7 (the highest level) of the Electronic Medical Record Application Evaluation by the American organization Healthcare Information and Management Systems Society. These achievements indicated the information systems in place in our hospital met the highest national and international standards, thereby minimizing the likelihood of recall bias. Furthermore, we addressed the confounding bias by adjusting for virtually all available relevant covariates through regression models. Secondly, relatively shorter follow-up periods (median $=2.97$ years) and a greater number of patients with missing information for variables or covariates $(n=322)$ is a concern in the present study. However, we found no difference between the included and excluding patients. Thirdly, it should be noted that FIGO stage I accounted for a higher proportion $(27.8 \%)$ of cases compared with other 
studies. This phenomenon might be attributed to the accidental diagnosis of EOC when checking for other diseases such as benign ovarian tumors as well as myoma. Furthermore, the Department of Obstetrics and Gynecology of China Medical University is the highest authority on EOC diagnosis in northeast China, potentially explaining the early diagnosis of EOC in the present study. Finally, we failed to obtain genotype data for all patients. Cozzi and colleagues [8] suggested that EOC cases with the minor allele rs1053878, which distinguishes the A1 and A2 alleles, had a $50 \%$ lower risk of death.

In summary, our data does not support an association between $\mathrm{ABO}$ blood type and the prognosis of EOC. Considering the controversy of this issue, additional cohort studies are warranted to confirm our findings.

\section{Acknowledgements}

This study was supported by grants from the Natural Science Foundation of China (No. 81602918 to Qi-Jun $\mathrm{Wu}$ ), the Doctoral Start-up Foundation of Liaoning Province (No. 201501007 to Qi-Jun Wu), the Younger research fund of Shengjing Hospital (Grant 2014sj09 to Qi-Jun Wu), and the Campus Research Fund of China Medical University (No. YQ20170002 to Qi-Jun $\mathrm{Wu}$ ).

Qi-Jun $\mathrm{Wu}$ was supported by the Fogarty International Clinical Research Scholars and Fellows Support Center at the Vanderbilt Institute for Global Health, funded by the Fogarty International Center, NIH, through an R24 Training Grant (D43 TW008313 to Xiao-Ou Shu).

\section{Author Contributions}

$\mathrm{LW}$ and $\mathrm{ZY}$ contributed equally to this work. $\mathrm{LW}, \mathrm{ZY}$, and Q-JW designed research; LW, YL, Y-NW, J-YG, Q-JW, and T-TG conducted research; LW, Q-JW, and T-TG analyzed data; LW, ZY, Q-JW, and T-TG wrote the draft. All authors read, reviewed and approved the final manuscript. Q-JW and T-TG had primary responsibility for final content.

\section{Competing Interests}

The authors have declared that no competing interest exists.

\section{References}

[1] Siegel RL, Miller KD, Jemal A. Cancer statistics, 2016. CA: A Cancer Journal for Clinicians 2016; 66: 7-30.

[2] Zheng H, Gao YN. Primary debulking surgery or neoadjuvant chemotherapy followed by interval debulking surgery for patients with advanced ovarian cancer. Chin J Cancer Res 2012; 24: 304-09.

[3] Lowe KA, Chia VM, Taylor A, et al. An international assessment of ovarian cancer incidence and mortality. Gynecologic Oncology 2013; 130: 107-14.

[4] Kim SI, Lee JW, Lee M, et al. Genomic landscape of ovarian clear cell carcinoma via whole exome sequencing. Gynecologic Oncology 2018; 148: $375-82$.
[5] Grisham RN, Iyer G, Garg K, et al. Braf mutation is associated with early stage disease and improved outcome in patients with low-grade serous ovarian cancer. Cancer 2013; 119: 548-54.

[6] Marinaccio M, Traversa A, Carioggia E, et al. [blood groups of the abo system and survival rate in gynecologic tumors]. Minerva Ginecol 1995; 47: 69-76.

[7] Zhou J, Yang LC, He ZY, et al. Prognostic impact of abo blood group on the survival in patients with ovarian cancer. Journal of Cancer 2015; 6: 970-75.

[8] Cozzi GD, Levinson RT, Toole $\mathrm{H}$, et al. Blood type, abo genetic variants, and ovarian cancer survival. Plos One 2017; 12: e175119.

[9] Liumbruno GM, Franchini M. Hemostasis, cancer, and abo blood group: the most recent evidence of association. J Thromb Thrombolysis 2014; 38: 160-66.

[10] Zhang BL, He N, Huang YB, et al. Abo blood groups and risk of cancer: a systematic review and meta-analysis. Asian Pac J Cancer Prev 2014; 15: 4643-50.

[11] Franchini M, Liumbruno GM, Lippi G. The prognostic value of abo blood group in cancer patients. Blood Transfus 2016; 14: 434-40.

[12] Hanprasertpong J, Jiamset I, Atjimakul T. Prognostic value of abo blood group in patients with early stage cervical cancer treated with radical hysterectomy with pelvic node dissection. Tumour Biol 2016; 37: 7421-30.

[13] Benedet JL, Bender $\mathrm{H}$, Jones HR, et al. Figo staging classifications and clinical practice guidelines in the management of gynecologic cancers. Figo committee on gynecologic oncology. Int J Gynaecol Obstet 2000; 70: 209-62.

[14] Duska LR, Kohn EC. The new classifications of ovarian, fallopian tube, and primary peritoneal cancer and their clinical implications. Annals of Oncology 2017; 28: i8-12.

[15] Oken MM, Creech RH, Tormey DC, et al. Toxicity and response criteria of the eastern cooperative oncology group. Am J Clin Oncol 1982; 5: 649-55.

[16] Charlson ME, Pompei P, Ales KL, et al. A new method of classifying prognostic comorbidity in longitudinal studies: development and validation. J Chronic Dis 1987; 40: 373-83.

[17] Li D, Pise MN, Overman MJ, et al. Abo non-o type as a risk factor for thrombosis in patients with pancreatic cancer. Cancer Med 2015; 4: 1651-58.

[18] Eastlund T. The histo-blood group abo system and tissue transplantation. Transfusion 1998; 38: 975-88.

[19] Jenkins PV, O'Donnell JS. Abo blood group determines plasma von willebrand factor levels: a biologic function after all? Transfusion 2006; 46: 1836-44.

[20] Franchini M, Frattini F, Crestani S, et al. Von willebrand factor and cancer: a renewed interest. Thrombosis Research 2013; 131: 290-92.

[21] Rumley A, Lowe GD, Sweetnam PM, et al. Factor viii, von willebrand factor and the risk of major ischaemic heart disease in the caerphilly heart study. Br J Haematol 1999; 105: 110-16.

[22] Sampson MT, Kakkar AK. Coagulation proteases and human cancer. Biochem Soc Trans 2002; 30: 201-07.

[23] Epstein AS, Soff GA, Capanu M, et al. Analysis of incidence and clinical outcomes in patients with thromboembolic events and invasive exocrine pancreatic cancer. Cancer 2012; 118: 3053-61.

[24] Hakomori S. Antigen structure and genetic basis of histo-blood groups a, b and o: their changes associated with human cancer. Biochim Biophys Acta 1999; 1473: 247-66.

[25] Franchini M, Liumbruno GM, Lippi G. The prognostic value of abo blood group in cancer patients. Blood Transfus 2016; 14: 434-40.

[26] Gao S, Worm J, Guldberg P, et al. Genetic and epigenetic alterations of the blood group abo gene in oral squamous cell carcinoma. International Journal of Cancer 2004; 109: 230-37.

[27] Le Pendu J, Marionneau S, Cailleau-Thomas A, et al. Abh and lewis histo-blood group antigens in cancer. Apmis 2001; 109: 9-31.

[28] Franchini M, Lippi G. The intriguing relationship between the abo blood group, cardiovascular disease, and cancer. Bmc Medicine 2015; 13: 7 .

[29] Pare G, Chasman DI, Kellogg M, et al. Novel association of abo histo-blood group antigen with soluble icam-1: results of a genome-wide association study of 6,578 women. Plos Genetics 2008; 4: e1000118.

[30] Ma $\mathrm{Q}$, Liu $\mathrm{W}$, Jia $R$, et al. Inflammation-based prognostic system predicts postoperative survival of esophageal carcinoma patients with normal preoperative serum carcinoembryonic antigen and squamous cell carcinoma antigen levels. World Journal of Surgical Oncology 2016; 14: 141.

[31] Gates MA, Xu M, Chen WY, et al. Abo blood group and breast cancer incidence and survival. International Journal of Cancer 2012; 130: 2129-37. 